\title{
EDITORIAL
}

\section{EUTANASIA EN BÉLGICA ¿UN MODELO PARA ESPAÑA?}

\author{
Asociación Federal pro Derecho a Morir Dignamente (AFDMD)
}

El debate sobre el derecho a morir y, más concretamente, sobre la existencia o no del derecho a recibir ayuda para morir, viene produciéndose abiertamente en el mundo occidental desde la primera mitad del siglo XX. Al calor de ese debate, en 1935 se constituyó en el Reino Unido la primera asociación ciudadana creada para reivindicar el derecho a la eutanasia con el expresivo nombre de "Exit" (actualmente denominada Voluntary Euthanasia Society). El movimiento continuó en los Estados Unidos de Norteamérica con la Euthanasia Society of America que, desde su fundación en 1938, reivindica el derecho a morir, a disponer de la propia vida, y su inclusión en la Carta de los Derechos Humanos Universales. A partir de los años 70 el movimiento pro-eutanasia se extendió a otros países, creándose la Federación Mundial de Sociedades pro Derecho a Morir (World Federation of Right to Die Societies o WFRDS) actualmente integrada por 44 asociaciones de 26 países. En España, gracias a iniciativas personales como la de Miguel Ángel Lerma en 1984 o Salvador Pániker posteriormente, este movimiento ciudadano lo representa la Asociación Federal Derecho a Morir Dignamente (AFDMD).

Promovido por estas asociaciones y por el conocimiento público de casos como el de Ramón Sampedro, en el último cuarto del siglo pasado el debate se abrió a la ciudadanía en general de la mano de una serie de procesos judiciales que trascendieron a la opinión pública y alcanzaron notoriedad tanto en Europa como en diversos estados de Norteamérica.
El debate en América se centró inicialmente en la existencia o no del derecho del enfermo a renunciar a un tratamiento salvador. En 1975, el caso de Karen Ann Quinlan en New Jersey llegó al Tribunal Supremo de dicho estado que declaró la existencia constitucional del derecho a morir amparado en el derecho a la privacy (lo que en nuestro medio es equivalente a la autonomía personal). El Tribunal Supremo de New Jersey anuló así la sentencia condenatoria del tribunal de primera instancia, declarando también el derecho de Karen, incapaz para decidir, a ser representada por sus padres. Fue el primer paso en el camino hacia la disponibilidad de la propia vida en Estados Unidos.

Lo que el proceso de Karen supuso de avance podría resultar hoy insignificante para una sociedad como la europea en la que los derechos sanitarios, especialmente la autonomía personal en la toma de decisiones, están plenamente amparados por leyes nacionales y por consensos internacionales. No era así para gran parte de la sociedad norteamericana de la época que creía en que la defensa de la vida, incluso por encima de la voluntad del individuo, era una obligación del Estado.

Desde luego, es mucho lo que se ha avanzado en Europa pero no deberíamos olvidar el largo peregrinaje judicial de Beppino Englaro, durante nueve años, hasta conseguir que en 2008, la Corte Suprema de Italia reconociera por fin a su hija Eluana el derecho a renunciar a la alimentación e hidrata- 
ción que la mantuvo en estado vegetativo permanente durante 17 años. Menos aún deberíamos olvidar los intentos por parte de la jerarquía católica de impedir ese derecho o la respuesta política de la mayoría parlamentaria conservadora cediendo a dichas presiones, promulgando en julio de 2011 una ley contra la eutanasia que priva a los pacientes de la decisión sobre los tratamientos al final de sus vidas, dejando las conclusiones trascendentales en manos del médico. O que, en la España de 2006, el cumplimiento de la voluntad de Inmaculada Echevarría de ser desconectada del respirador artificial que la mantenía con vida precisó de la intervención de la Comisión Autonómica de Ética e Investigación de Andalucía y del Consejo Consultivo de Andalucía, en un procedimiento que se prolongó cinco meses. Ello a pesar de la Ley General de Sanidad (1986), de la de Autonomía del Paciente (2002), y del Convenio Europeo sobre Derechos Humanos y Biomedicina de 1996 ("Convenio de Oviedo") en vigor desde enero de 2000 en España, como país firmante del mismo. Conviene remarcar sin embargo que, al contrario que en Italia, la Junta de Andalucía respondió a las dificultades promulgando una ley de derechos al final de la vida para que ningún andaluz se viera limitado en el ejercicio de su derecho a decidir sobre su persona.

En Europa, concretamente en Holanda, a partir de 1973, el debate sobre la eutanasia se desarrolló en el ámbito judicial a raíz de sucesivas sentencias sobre casos de conductas eutanásicas que, siendo condenatorias, indicaron en sus considerandos las condiciones que, de haberse cumplido en el caso juzgado, habrían dado lugar a una sentencia absolutoria. De esta forma fueron los tribunales los que marcaron las circunstancias en las que la causación de la muerte bajo petición podría ser moral y jurídicamente aceptable. La Real Asociación Médica de Holanda jugó un importante papel en todo el proceso que culminó con la aprobación de la Ley de eutanasia en 2001. Tras Holanda, en un debate casi simultáneo, en 2002 Bélgica despenalizó y reguló la práctica de la eutanasia bajo determinados supuestos. Más tarde, en 2009, Luxemburgo se añadió a los países que la han regulado en Europa, demostrando que sociedades modernas y avanzadas pueden profundizar en el reconocimiento del derecho ciudadano a decidir sobre la propia vida sin que ello suponga el fin de la civilización occidental.

En este número de la Revista Española de Salud Pública, los doctores Simón y Barrio nos ofrecen un interesante análisis del proceso que llevó hasta la aprobación de la eutanasia en Bélgica. Para la AFDMD es de justicia reconocer públicamente a los autores, especialmente al doctor Pablo Simón, su contribución a la clarificación del debate sobre la muerte digna en nuestro país en los últimos años. Se suma a dicha contribución este artículo que contiene además una interesante propuesta de que el proceso belga sea tomado como modelo para el debate sobre la eutanasia en España, debate (que evidentemente compartimos) que en opinión de los autores habrá de producirse más pronto o más tarde.

Los autores basan su propuesta en determinadas similitudes existentes entre ambas sociedades.

En nuestra condición declarada de firmes partidarios del derecho a decidir en libertad todos los aspectos de nuestras vidas, incluido su proceso final, no podemos por menos que agradecer este trabajo en el que, como en anteriores ocasiones, los autores ofrecen una visión dialogantemente serena de lo que se ha venido en denominar "muerte digna" frente a posiciones intransigentes basadas en la concepción de la sacralidad de la vida que nuestra Asociación, con todo derecho, no comparte.

Especialmente interesante y reveladora nos parece su descripción de la posición de 
dos colectivos muy importantes en el proceso de despenalización de la eutanasia: el de los paliativistas, agrupados en la Federación Flamenca de Cuidados paliativos, y el de la Iglesia Católica. También, aunque los autores no lo analizan junto con los dos anteriores, el de los Partidos Políticos.

En nuestra opinión, el comportamiento de estos tres colectivos en nuestro país difiere hasta ahora muy significativamente del de sus correspondientes en Bélgica, hasta el punto de considerar muy difícil que puedan desempeñar en un futuro relativamente cercano un papel ni tan siquiera permisivo del proceso legalizador de la eutanasia.

Comenzaremos con la postura de los paliativistas. Al contrario que sus colegas belgas, al menos los responsables institucionales de los Cuidados Paliativos, en España mantienen una oposición radical a la eutanasia que reiteradamente niegan como una opción legítima, la única admisible para unos pocos pacientes (tal vez el 2 o el $3 \%$ como máximo) que, o bien experimentan un sufrimiento total a causa de su enfermedad o simplemente rechazan vivir un proceso de deterioro progresivo que consideran indigno de ser vivido. Partiendo de una afirmación que en nuestra experiencia es falsa: que los pacientes con acceso a unos buenos cuidados paliativos no sienten la necesidad de solicitar la eutanasia, cierran los ojos a la realidad de que para un segmento de la población, pequeño por ahora pero digno de todo respeto, su decisión de solicitar ayuda para morir no se debe al dolor físico sino al sentimiento de pérdida de su dignidad asociado a la incapacidad de valerse por sí mismo y a la dependencia de los demás. Para estos pacientes ni los mejores cuidados paliativos son capaces de resolver su situación. Sin embargo, estos se nos presentan como un antídoto contra la eutanasia. La experiencia belga demuestra que no sólo no hay oposición entre paliativos y eutanasia sino que ésta debe integrarse en la atención paliativa que, de otro modo no puede dar respuesta a todas las necesidades de sus pacientes.
En DMD hemos defendido y reclamado siempre como un derecho fundamental de los enfermos el acceso real a los cuidados paliativos y hemos denunciado el abandono terapéutico al que se ven sometidos demasiados pacientes que, rechazados por la medicina curativa, no alcanzan cuidados paliativos o para hacerlo tienen que renunciar al marco de intimidad del propio domicilio. Pero con la misma firmeza, rechazamos la oposición paliativos-eutanasia que en ocasiones parece más motivada por el interés de expansión profesional (interés legítimo en tanto no se intente disimular) que por el de los pacientes. El trabajo de Simón y Barrio muestra bien a las claras que la aprobación de la eutanasia en Bélgica se ha acompañado de un gran desarrollo de la atención paliativa, mayor que la española, y de una calidad de muerte de los belgas muy superior a la de los españoles. No es la falta de paliativos lo que lleva a solicitar la eutanasia y, en consecuencia, no tiene razón de ser postergar el debate hasta que los paliativos sean universales. Mucho tiene que cambiar la concepción de los paliativistas hacia las posiciones integradoras de sus colegas belgas para que su concepto de hasta donde debe llegar la autonomía personal y cuáles son las obligaciones de los médicos en general no siga siendo un freno para la opción eutanásica en nuestro país.

La doctrina oficial de la Iglesia Católica sobre la indisponibilidad de la vida, por ser un don sagrado del que sólo somos administradores, no ha sido un impedimento para que la eutanasia se practique en sus numerosos centros sanitarios, como se nos informa en el trabajo comentado. Tal vez por la añoranza de tiempos recientes en los que, en España, la visión de la Iglesia se trasladaba directamente a las leyes, parece impensable una postura de la jerarquía mismamente (o mínimamente) tolerante entre nosotros. Ningún gobernante puede esperar otra cosa de la jerarquía católica respecto de una hipotética aprobación de la eutanasia que una cerrada oposición en todos los frentes, incluido el de 
una presión sobre los órganos de decisión civil, inaceptable en un estado constitucionalmente aconfesional como es el nuestro.

Terminaremos aportando nuestra opinión respecto al diferente comportamiento de los partidos políticos belgas y españoles. Como señalan los autores, el Partido CristianoDemócrata en el poder durante 40 años, se opuso a la legalización de la eutanasia y rechazó cuantas iniciativas legislativas fueron presentadas por partidos de la izquierda, incluso tras el dictamen favorable a la legalización emitido por el Comité Asesor de Bioética. Fue preciso un cambio de gobierno para que la coalición entrante aprobase la ley de eutanasia.

La situación en España resulta hasta cierto punto paradójica: el Partido Socialista ha tenido una posición cambiante sobre la eutanasia, desde ser una propuesta en su programa electoral hasta rechazar la oportunidad del debate negando la suficiente madurez de los ciudadanos. De tal manera que las reiteradas propuestas de abolición del artículo 143 del Código Penal presentadas en el Parlamento por grupos minoritarios de izquierdas han sido rechazadas con los votos aunados del Partido Popular en la oposición y los del Partido Socialista en el gobierno. No es fácil entender tal falta de determinación política en este asunto, pero una de sus causas pudiera ser el temor a irritar a la jerarquía católica siempre dispuesta a descalificar las decisiones que no se ajustan a sus criterios de lo moralmente aceptable.

A pesar de estos antecedentes, no nos parece impensable que en un futuro, si llegara a plantearse una situación política en la que se requiera una mayoría multicolor para formar gobierno, las minorías de izquierdas tuvieran la oportunidad de incluir la eutanasia entre las condiciones para apoyarlo. Si bien la experiencia hasta hoy es que el Partido Socialista ha tenido siempre más facilidad y propensión a pactar con la derecha nacionalista que con la izquierda minorita- ria, es posible que el rearme ideológico que puede iniciarse tras la reciente derrota electoral pueda cambiar esa tendencia.

$¿$ Cabe entonces descartar un avance hacia la aprobación de la eutanasia en España a corto o medio plazo? Nosotros creemos que sí en el corto plazo. No será el Partido Popular el que mueva un dedo a favor de la eutanasia. Pero al igual que no es descartable por completo un cambio de panorama político en España, a medio plazo, tampoco lo es un escenario europeo de desalojo de los partidos de derecha como consecuencia de la crisis financiera, a favor de partidos de izquierda que puedan propiciar acuerdos transnacionales, como en su día el Convenio Europeo de Derechos Humanos y Biomedicina, con fuerza de ley en los estados.

En todo caso, esta asociación seguirá trabajando con la ciudadanía, con los sanitarios y con los partidos políticos sensibles al tema, proporcionando elementos de convicción para que el debate sobre la conveniencia de regular y despenalizar la eutanasia se resuelva en el sentido de más libertad y más autonomía personal, consiguiendo que las decisiones fundamentales sobre nuestra muerte no sigan en manos de otros, sean obispos, médicos o políticos.

Trabajos como el de Simón y Barrio ayudan a caminar en el sentido adecuado, demostrando que incluso en países de tradición católica y conservadora, la legalización de la eutanasia no sólo es posible sino que incluso mejora la atención sanitaria de la población. 